\title{
Minute gastric adenocarcinoma of the fundic-gland type with submucosal invasion
}

A 64-year-old woman without Helicobacter pylori infection underwent an esophagogastroduodenoscopy during a health examination. A 2-mm flat lesion (0-IIb) with faded color and harboring a regular arrangement of collecting venules was detected at the greater curvature of the gastric fundus. Narrow-band imaging (NBI) showed a distinct whitish lesion. Magnifying endoscopy with NBI revealed a regular microsurface and microvascular pattern without a demarcation line, and a noncancer diagnosis was made [1]. However, as the endoscopic features on white-light imaging still strongly suggested neoplastic lesion in the background of mucosa not infected by $H$. pylori, a biopsy was taken. Histologically, a gastric adenocarcinoma resembling fundic gland cells with submucosal invasion was seen ( Fig. 1). A pathological diagnosis of gastric adenocarcinoma of the fundic-gland type [2,3] was further confirmed by immunohistochemical staining.

Endoscopic submucosal dissection was performed. No residual tumor was detected in the resected specimen, indicating that the tumor had been completely removed by endoscopic biopsy ( $\triangleright$ Video 1). Despite the lesion being the smallest ever reported, submucosal invasion was seen histologically. Adenocarcinoma rather than adenoma is appropriate naming for this kind of lesion. As gastric cancer without $H$. pylori infection is expected to become more prevalent, we believe that the endoscopic features of this case can help endoscopists to detect more gastric adenocarcinomas of the fundic-gland type at an earlier phase to ensure effective treatment.

Endoscopy_UCTN_Code_TTT_1AO_2AG

\section{Competing interests}

The authors declare that they have no conflict of interest.
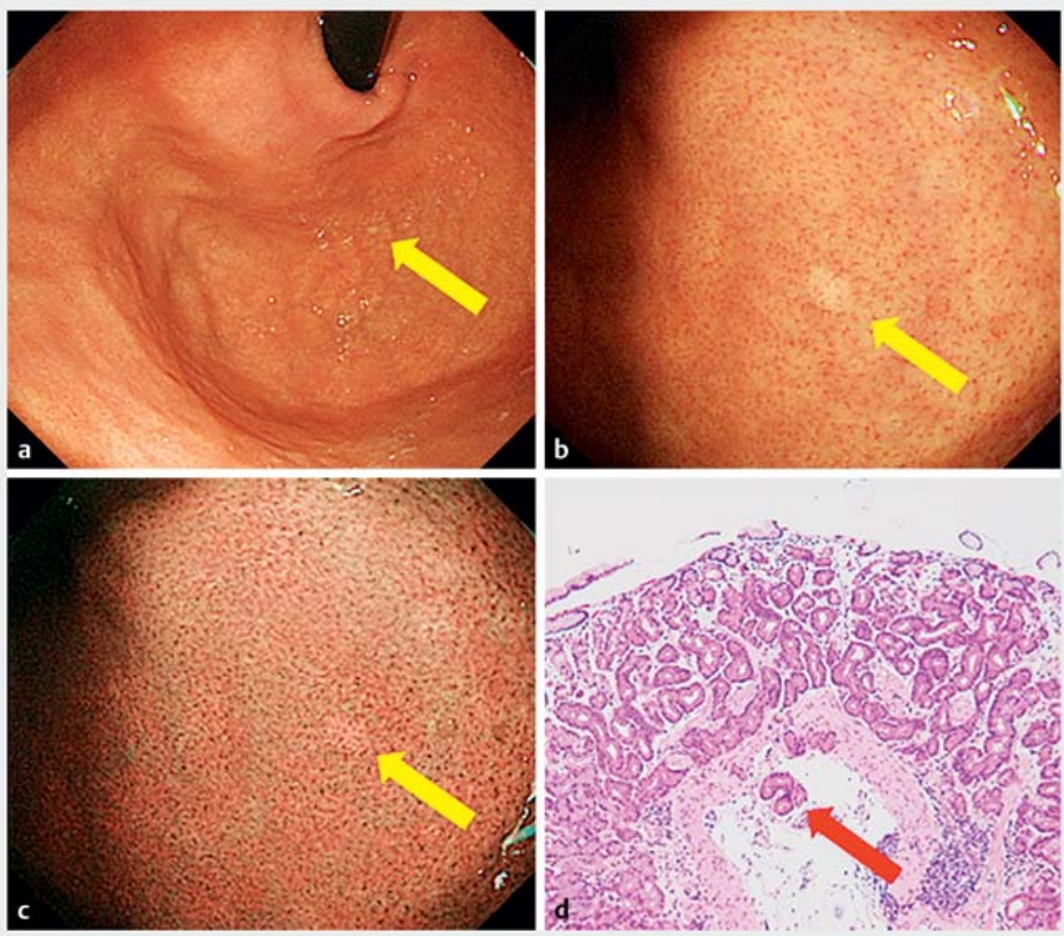

- Fig. 1 A 2-mm flat lesion (0-Ilb) with faded color and harboring a regular arrangement of collecting venules was detected at the greater curvature of the gastric fundus (yellow arrow): a distant view; b closer view. c Narrow-band imaging showed a distinct whitish lesion (yellow arrow). d A biopsy specimen showed a gastric adenocarcinoma of the fundic-gland type with submucosal invasion (red arrow).
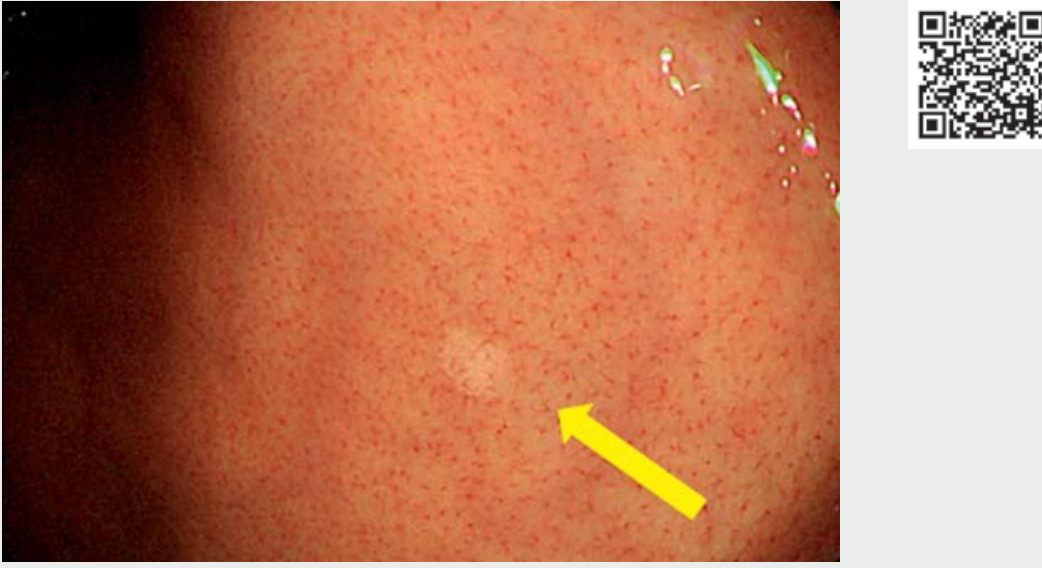

Video 1 Minute gastric adenocarcinoma of the fundic-gland type with submucosal invasion. 
Tsutomu Takeda ${ }^{1} \stackrel{\oplus \text {, Hiroya Ueyama }}{ }{ }^{1} \stackrel{\oplus, \text { Kuang-I }}{ }$ $\mathrm{Fu}^{2}$, Satoshi Murata ${ }^{3}$, Akihito Nagahara ${ }^{1}$

1 Department of Gastroenterology, Juntendo University School of Medicine, Tokyo, Japan

2 Department of Endoscopy, Kanma Memorial Hospital, Tokyo, Japan

3 Murata Gastrointestinal Endoscope clinic, Tokyo, Japan

\section{Corresponding author}

\section{Hiroya Ueyama, MD, PhD}

Department of Gastroenterology, Juntendo University School of Medicine, 2-1-1 Hongo, Bunkyo-ku, Tokyo 113-8421, Japan

psyro@juntendo.ac.jp
[1] Muto M, Yao K, Kaise M et al. Magnifying endoscopy simple diagnostic algorithm for early gastric cancer (MESDA-G). Dig Endosc 2016; 28: 379-393

[2] Ueyama H, Yao T, Nakashima Y et al. Gastric adenocarcinoma of fundic gland type (chief cell predominant type): proposal for a new entity of gastric adenocarcinoma. Am J Surg Pathol 2010; 34: 609-619

[3] Ueyama H, Matsumoto K, Nagahara A et al. Gastric adenocarcinoma of the fundic gland type (chief cell predominant type). Endoscopy $2014 ; 46$ : 153-157

Bibliography

Endoscopy 2022; 54: E468-E469

DOI 10.1055/a-1625-5865

ISSN 0013-726X

published online 27.9.2021

(c) 2021. Thieme. All rights reserved.

Georg Thieme Verlag KG, Rüdigerstraße 14,

70469 Stuttgart, Germany
ENDOSCOPY E-VIDEOS

https://eref.thieme.de/e-videos

回屌 Endoscopy E-Videos is an

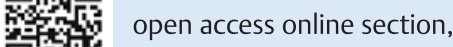

靣跣: reporting on interesting cases and new techniques in gastroenterological endoscopy. All papers include a high quality video and all contributions are freely accessible online. Processing charges apply (currently EUR 375), discounts and wavers acc. to HINARI are available.

This section has its own submission website at

https://mc.manuscriptcentral.com/e-videos 